\title{
Examining Whether Smart Meters Have Been Used Smartly: A Case Study of Residential Electricity Customers in Vermont
}

\author{
Qingbin Wang*, Samantha Lewandowski \\ Department of Community Development \& Applied Economics, University of Vermont, Burlington, USA \\ Email address: \\ qwang@uvm.edu (Q. Wang), slewando@uvm.edu (S. Lewandowski) \\ ${ }^{*}$ Corresponding author

\section{To cite this article:} \\ Qingbin Wang, Samantha Lewandowski. Examining Whether Smart Meters Have Been Used Smartly: A Case Study of Residential \\ Electricity Customers in Vermont. International Journal of Sustainable and Green Energy. Vol. 6, No. 5, 2017, pp. 76-83. \\ doi: $10.11648 /$ j.ijrse.20170605.12
}

Received: July 10, 2017; Accepted: July 26, 2017; Published: October 16, 2017

\begin{abstract}
Approximately $92 \%$ of electricity meters in Vermont, and more than $40 \%$ across the United States, have been replaced with smart meters due to their potential to improve grid efficiency and reduce electricity costs, but there is very limited information on whether smart meters are benefitting or being efficiently used by electricity customers. In this study, quantitative analysis of primary data from statewide surveys in Vermont is used to address several questions on consumer behavior and opinions towards smart meters. The empirical results indicate that less than $50 \%$ of the surveyed customers reported having a smart meter and, for those who did report having a smart meter, less than $20 \%$ of them thought that the smart meter had reduced their electricity use. Also, there were significant differences in demographic factors and concerns about the potential impacts of smart meters on health and privacy between those who reported having a smart meter and those who did not. Furthermore, the respondents did report some interest in receiving additional information on smart meters. In all, these findings suggest that there are a number of ways utility companies and other educational entities, such as Extension, can improve the efficacy of smart meter utilization.
\end{abstract}

Keywords: Smart Meter, Smart Grid, Customer Education, Electricity Customer, Vermont

\section{Introduction}

In the United States, around $\$ 8$ billion has been spent on smart meter installation, with $\$ 3.4$ billion from federal funds and $\$ 4.6$ billion from other sources [1]. Over 50 million smart meters have been installed, and around $43 \%$ of homes now have a smart meter [2]. While traditional analog electric meters are capable of only recording the total amount of electricity a customer consumes, digital smart meters allow for two-way communication between utility companies and households and for electricity consumption to be measured hourly or even more frequently [3]. Smart meters have the potential to benefit utility companies by reducing congestion in transmission lines, limiting the severity of blackouts [4], and lowering labor costs associated with meter readers [5]. Customers may use the real-time or nearly-real-time pricing information from smart meters to shift electricity consumption away from peak demand to times when it is less costly $[4,6]$. Customers can also use data from smart meters to attain a more in-depth look at their electricity use, such as how much electricity is consumed throughout the day. Such awareness may encourage customers to use less energy. Smart meters may also yield environmental benefits, as they enable utility companies and customers to use electricity more efficiently, thus reducing carbon dioxide emissions [4].

Despite the significant investments made in smart meters and the many benefits they could provide, not much is known about how effectively customers are using smart meter information. The purpose of this study is to better understand how smart meters are utilized by electricity customers, using primary data from two statewide surveys conducted in Vermont in 2015 and 2016. Vermont provides an excellent case for studying the utilization of smart meters, as around $\$ 137$ million has been spent to install 305,464 smart meters in the state [7], approximately $92 \%$ of electricity meters in Vermont are now smart meters, and less than $5 \%$ of 
electricity customers have opted out of having a smart meter installed [8]. Specifically, primary data collected from the statewide surveys are used to assess the self-reported effects of smart meters on electricity use, the demographic differences between those who reported having a smart meter and those who did not, consumer concerns about smart meters' potential impacts on health and privacy, and consumers' interest in receiving additional information on smart meters. In light of the huge public investment in smart meters and limited information on how consumers have used this technology, the results from this paper are expected to be helpful for utility companies and other entities that are working on energy-related issues in their communities.

\section{Data Collection}

Data used in this study were collected by the Center for Rural Studies at the University of Vermont as part of the 2015 and 2016 Vermonter Polls. For the 2015 survey, 2,354 households were contacted by telephone, and 619 people completed the survey, yielding a response rate of $26.3 \%$. In 2016, 2,547 households were contacted by telephone, and 684 people completed the survey, yielding a response rate of $26.9 \%$. The 2015 and 2016 surveys had margins of error of plus or minus $4 \%$ and $3.9 \%$ respectively, and both surveys had a confidence interval of $95 \%$. Included in these surveys were four questions on smart meters that assessed the following: (1) whether respondents thought they had a smart meter, (2) whether respondents thought that having a smart meter reduced their electricity use, (3) whether respondents were concerned about any potential impacts on health due to smart meters, and (4) whether respondents were concerned about any potential impacts on privacy due to smart meters. In addition to these four questions, the 2016 survey also included a question on whether customers were interested in receiving additional information on smart meters. The data for these five questions and relevant demographic variables were analyzed through descriptive analysis, Chi-square tests, and binary logistic regressions.

\section{Analysis and Results}

The survey data were coded and analyzed in SPSS (Statistical Package for Social Sciences), and the results are presented in six subsections: (1) summary statistics and differences between respondents who reported having smart meters and respondents who did not, (2) analysis of the factors affecting whether respondents reported having a smart meter, (3) respondents' lack of awareness of installed smart meters, (4) impacts of smart meter installation on electricity consumption, (5) respondents' concerns about smart meters' potential impacts on health and privacy, and (6) respondents' interest in receiving additional information on smart meters.

\subsection{A Descriptive Analysis}

Table 1 reports the summary statistics for the merged data of years 2015 and 2016, except for three variables: housing type, which was only included in the 2015 survey, and concern about potential privacy and health impacts, which were included in both the 2015 and 2016 surveys, but used slightly different Likert-type scales and so could not be combined into one variable. Privacy and health concerns reported in the table are from 2016 data only. Summary statistics are provided for the whole sample and two subgroups: those who reported having a smart meter (Group A) and those who did not (Group B).

The summary statistics reported in Table 1 and the results of Chi-square tests for determining whether the difference between Group A and Group B is significant suggest the following five findings: First, those who reported having a smart meter were more likely to be male $(55.2 \%)$ than female $(44.8 \%)$. This result suggests that Vermont males are more likely to report that they have a smart meter than Vermont females.

Second, those who reported having a smart meter (Group A) were more likely to live in single-family dwellings and be home-owners than those who did not report having a smart meter (Group B). In Group A, 78.4\% lived in single-family dwellings, as compared to $70.0 \%$ in Group B. Additionally, $90.4 \%$ in group A owned their homes, as compared to $78.9 \%$ in Group B. A potential driver of this relationship is that those who live in single-family dwellings may be more likely to own than rent and therefore live in one place for longer periods of time than those living in apartments. Home ownership and longer duration of occupancy may lead to greater awareness of meter type. The overall rate of homeownership in Vermont for 2015 was $71.3 \%$ [9].

Third, those who reported having a smart meter were more likely to be 41 or over $(89.2 \%)$ as compared to those who did not report having a smart meter $(82.4 \%)$. Conversely, those who did not report having a smart meter were more likely to be $18-40(17.5 \%)$ as compared to those who reported having a smart meter $(10.8 \%)$. This finding suggests that those who report having a smart meter are slightly older than those who do not

Fourth, those who reported having a smart meter (Group A) were more likely to be "not concerned at all" about smart meters' potential health impacts than those who did not report having a smart meter (Group B), and Group B was more likely to be unsure about the meters' potential health impacts than Group A. In Group A, 64.5\% of respondents were "not concerned at all" about potential health impacts, as compared to only $36.9 \%$ of respondents in Group B. Additionally, respondents in Group B were a little more than 2.5 times as likely $(47.1 \%)$ as those in Group A (18.5\%) to report that they were "not sure" whether they were concerned about possible health impacts of smart meters.

Fifth, those who reported having a smart meter were more likely to be "not concerned at all" about the potential privacy impacts of smart meters than those who did not report having a smart meter, and those who did not report having a smart meter were more likely to be unsure about the smart meter's potential privacy impacts than those who reported having a smart meter. In Group A, 63.2\% reported being "not 
concerned at all" about smart meters' potential impacts on their privacy, as compared to $41.3 \%$ of Group B. Additionally, Group B was much more uncertain about privacy concerns, with $37.2 \%$ reporting being "not sure," compared to only $9.7 \%$ of Group A respondents.

Table 1. Summary statistics by respondent groups.

\begin{tabular}{|c|c|c|c|c|}
\hline & $\begin{array}{l}\text { Whole sample } \\
(\mathrm{n}=1297)\end{array}$ & $\begin{array}{l}\text { Group A:Respondents who } \\
\text { reported having a smart meter } \\
(n=608)\end{array}$ & $\begin{array}{l}\text { Group B: Respondents who did } \\
\text { not report having a smart meter } \\
(n=689)\end{array}$ & Chi-square $\left(x^{2}\right)$ \\
\hline Gender & & & & $\mathrm{x}^{2}=26.10 * * *$ \\
\hline Female & 52.3 & 44.8 & 59.2 & \\
\hline Male & 47.7 & 55.2 & 40.8 & \\
\hline Education & & & & $x^{2}=4.65$ \\
\hline No diploma & 2.0 & 2.4 & 1.7 & \\
\hline HS graduate or GED & 18.9 & 17.5 & 20.1 & \\
\hline Some college & 15.5 & 15.9 & 15.2 & \\
\hline Associate/technical degree & 10.7 & 12.1 & 9.2 & \\
\hline Bachelor's degree & 26.3 & 26.0 & 26.7 & \\
\hline Graduate/professional & 26.6 & 26.1 & 27.1 & \\
\hline Housing Type ${ }^{I}$ & & & & $x^{2}=6.87 * *$ \\
\hline Single-family dwelling & 73.9 & 78.4 & 70.0 & \\
\hline Unit in multi-family dwelling & 19.8 & 15.3 & 23.8 & \\
\hline Other & 6.3 & 6.3 & 6.2 & \\
\hline Housing Tenure & & & & $\mathrm{x}^{2}=30.34 * * *$ \\
\hline Own & 84.4 & 90.4 & 78.9 & \\
\hline Rent & 15.6 & 9.6 & 21.1 & \\
\hline Age Group & & & & $\mathrm{x}^{2}=16.12 * * *$ \\
\hline $18-30$ & 5.1 & 3.1 & 6.8 & \\
\hline $31-40$ & 9.3 & 7.7 & 10.8 & \\
\hline $41-50$ & 13.3 & 15.6 & 11.2 & \\
\hline $51-60$ & 22.4 & 22.7 & 22.2 & \\
\hline 61 and over & 49.9 & 50.9 & 49.0 & \\
\hline Concern about health impacts ${ }^{\mathrm{II}}$ & & & & $\mathrm{x}^{2}=71.28 * * *$ \\
\hline Not concerned at all & 50.4 & 64.5 & 36.9 & \\
\hline A little concerned & 7.2 & 8.5 & 6.0 & \\
\hline Concerned & 5.1 & 5.5 & 4.9 & \\
\hline Very concerned & 4.2 & 3.0 & 5.1 & \\
\hline Not sure & 33.1 & 18.5 & 47.1 & \\
\hline Concern about privacy impacts ${ }^{\text {III }}$ & & & & $\mathrm{x}^{2}=73.37 * * *$ \\
\hline Not concerned at all & 51.9 & 63.2 & 41.3 & \\
\hline A little concerned & 10.3 & 12.8 & 8.0 & \\
\hline Concerned & 7.7 & 8.2 & 7.2 & \\
\hline Very concerned & 6.2 & 6.1 & 6.3 & \\
\hline Not sure & 23.9 & 9.7 & 37.2 & \\
\hline
\end{tabular}

**The difference between the two groups is significant at the 0.95 significance level.

*** The difference between the two groups is significant at the 0.99 significance level.

IThese results are only for 2015 data, as this variable was not included in the 2016 survey ( $\mathrm{n}=592)$.

${ }^{\text {II }}$ These results are only for 2016 data, as slightly different Likert-type scales were used in the 2015 survey $(\mathrm{n}=680)$.

${ }^{\mathrm{III}}$ These results are only for 2016 data, as slightly different Likert-type scales were used in the 2015 survey (n=678).

The findings on respondents' concern about potential privacy impacts due to smart meters were similar to those on concern about potential health impacts due to smart meters. The percentage of electricity customers who have opted out of smart meter installation in Vermont is only $3 \%$ to $5 \%$ [8], but concerns that smart meters could adversely impact health and privacy represent two possible reasons for opting out.

\subsection{A Regression Analysis}

While the descriptive analysis reported above provides useful information on the factors for those who reported having a smart meter and those who did not, one limitation of such results is that the impact of each variable is analyzed without controlling for the impacts of other variables.
Regression analysis can overcome this limitation by estimating the impact of each independent variable on the dependent variable while other independent variables are controlled. A binary logistic regression is used in this study because the dependent variable is a binary variable. The estimation results of the binary logistic regression model are reported in Table 2. For the dependent variable, $\mathrm{Y}=1$ indicates that the respondent reported having a smart meter, and $\mathrm{Y}=0$ denotes "otherwise," meaning that the respondent did not report having a smart meter, either by responding "no" or that she or he did not know whether she or he had one.

While SPSS software provides several statistics on the goodness of fit of binary logistic regressions, the most 
relevant statistics are those concerning the power of prediction. This estimated model correctly predicts whether one reports having a smart meter for $61.5 \%$ of respondents (59.8\% for the respondents who reported having a smart meter and $63.0 \%$ for the respondents who did not report having a smart meter). Though this prediction power is not very high, it is within the range of many empirical studies using cross-sectional survey data [10]. Exp (B) in the last column of Table 2 is the exponentiation of the $\beta$ s and can be interpreted as the marginal impact of the independent variables on the odds for the dependent variable to be 1 . The results from this regression analysis suggest five major findings: (1) The odds of females reporting having a smart meter are $43.7 \%$ less than the odds of males reporting having a smart meter. (2) For those who have health concerns about smart meters, their odds of reporting having a smart meter are $36.8 \%$ less than those who did not report having such concerns. (3) In contrast, for those who have privacy concerns about smart meters, their odds of reporting having a smart meter are $45.0 \%$ greater than those who did not report having such concerns. The reason those who have health concerns about smart meters are less likely to report having them, while those who have privacy concerns about smart meters are more likely to report having them (as compared to those who did not express such concerns), is unclear. This contrast was not expected, and more primary data are needed to examine the possible reason(s) behind these results. (4) The odds of those renting a home reporting having a smart meter are $63.1 \%$ less than the odds of those owning a home reporting having a smart meter. (5) Last, the odds of those who did not have a diploma reporting having a smart meter are $131 \%$ greater than the odds of those with a higher level of education reporting having a smart meter.

Table 2. Logit regression results ( $Y=1$ indicates reporting having a smart meter and $Y=0$ indicates otherwise) $(n=1139)$.

\begin{tabular}{llll}
\hline Variable & Definition & B & Exp (B) \\
\hline Gender & 1 for female and 0 for male & $-0.574^{* * *}$ & 0.563 \\
Year & 1 if 2016 and 0 if 2015 & 0.096 & 1.100 \\
Health impact & 1 if yes (some level of concern) and 0 otherwise & $-0.459^{* *}$ & 0.632 \\
Privacy impact & 1 if yes (some level of concern) and 0 otherwise & $0.371^{* *}$ & 1.450 \\
Rentorown & 1 if rent and 0 if own & $-0.996^{* * *}$ & 0.369 \\
Pplhh & Number of people in household & -0.027 & 0.974 \\
Education & Level of education & & 2.309 \\
& 1 if no diploma and 0 otherwise & $0.837^{*}$ & 0.995 \\
& 1 if HS graduate/GED and 0 otherwise & -0.005 & 1.183 \\
& 1 if some college and 0 otherwise & 0.168 & 1.228 \\
Area & 1 if associate/technical degree and 0 otherwise & 0.205 & 0.989 \\
& 1 if bachelor's degree and 0 otherwise & -0.011 & 0.984 \\
Age & Living in a rural, suburban, or urban area & -0.016 & 1.035 \\
& 1 if rural and 0 otherwise & 0.035 & 0.688 \\
& 1 if suburban and 0 otherwise & -0.374 & 0.786 \\
Constant & 1 if $18-30$ and 0 otherwise & -0.240 & 1.382 \\
\hline
\end{tabular}

*The difference between the two groups is significant at the 0.90 significance level.

**The difference between the two groups is significant at the 0.95 significance level.

*** The difference between the two groups is significant at the 0.99 significance level.

\subsection{Lack of Awareness of Installed Smart Meters}

Many Vermont residents have a smart meter installed, but do not know it. Although about $92 \%$ of Vermont's electricity meters were smart meters by 2015 [8], only $45 \%$ of survey respondents in 2015 and $48.6 \%$ in 2016 reported having a smart meter. This means that close to half of Vermont's electricity customers were unaware that they had a smart meter at the time of the surveys. Although the percentage of respondents who reported having a smart meter was still relatively low in 2016, it did increase by 3.6 percentage points from 2015. However, obviously, to maximize the benefits from smart meters, electricity customers must first be aware that they have them. Many of the benefits of smart meters depend on electricity customers changing their electricity consumption in response to the nearly real-time pricing information that smart meters provide, which would be very difficult to do if customers are unaware that they have a smart meter. One possible exception to this would be if customers are nonetheless accessing the nearly real-time pricing information that smart meters provide, but are not changing their electricity consumption in response to this information.

\subsection{Impacts of Smart Meter Utilization on Electricity Consumption}

Having a smart meter has not reduced the electricity consumption of many Vermont residents. In 2015, among respondents who knew that they had a smart meter, only $2.2 \%$ reported that having a smart meter "significantly reduced" their electricity use, and $9.6 \%$ reported that having a smart meter reduced their electricity use "a little bit." 
$63.7 \%$ of respondents reported that the smart meter did not change their electricity use, and $24.5 \%$ of respondents were unsure whether the smart meter affected their electricity use. In 2016, among respondents who knew that they had a smart meter, only $3.1 \%$ reported that having a smart meter "significantly reduced" their electricity use, and $14.1 \%$ reported that having a smart meter reduced their electricity use "a little bit." $72.4 \%$ of respondents reported that the smart meter did not change their electricity use, and $10.4 \%$ of respondents were unsure whether the smart meter affected their electricity use. In 2016, as compared to 2015, an additional 5.4 percentage points of respondents reported that the smart meter had reduced their electricity use, and an additional 8.7 percentage points of respondents also reported that the smart meter had not changed their electricity use. The year of the survey did have a significant impact $\left(\mathrm{x}^{2}=3.27, p=.07\right)$ on whether one reported electricity reduction as the result of having a smart meter, with those in 2016 being more likely to report a reduction in electricity consumption as the result of having a smart meter than those in 2015 .

There may be several reasons why reduced electricity consumption among those who report having smart meters has not been prevalent. First, smart meter customers may be shifting when they consume electricity, but not necessarily reducing their consumption. Another possible reason is that those who have smart meters are not accessing the information they provide $[5,11]$ and are not changing their behavior as a result. Ensuring that the information provided by smart meters is easily accessible - e.g., via in-home displays, the electricity bill, and online tools and apps-can help to promote a greater change in consumers' electricity consumption $[5,11,12]$. In-home displays seem especially promising, with research showing that the most effective way to get smart meter users to shift and reduce electricity consumption may be through combining in-home displays that show real-time pricing information with dynamic electricity pricing $[13,14]$. However, dynamic pricing structures and in-home displays appear to be limited in Vermont $[15,16]$, thus reducing incentives for electricity customers to shift or reduce their electricity consumption.

\subsection{Concerns About Smart Meters' Potential Impacts on Health and Privacy}

As Figsure 1 and 2 show, while some Vermont residents were concerned about the potential impacts of smart meters on their health and privacy, a majority of them were not. Previous research by Hess [17] has shown that, nationally, some of the most outspoken opposition to smart meters arises from health and/or privacy concerns. Respondents in each year were more likely to report being concerned about potential privacy impacts than health impacts. In 2015, respondents were a little over 2 times more likely to report being concerned about the potential impacts of smart meters on their privacy $(18.8 \%)$ than health $(9.2 \%)$. In 2016, respondents were around 1.5 times more likely to report being concerned about the potential impacts of smart meters on privacy $(24.2 \%)$ than health $(16.5 \%)$. Overall though, respondents were much more likely to be unconcerned or unsure about potential impacts on health and privacy due to smart meters.

\section{- Concern about health impacts \\ - Concern about privacy impacts}

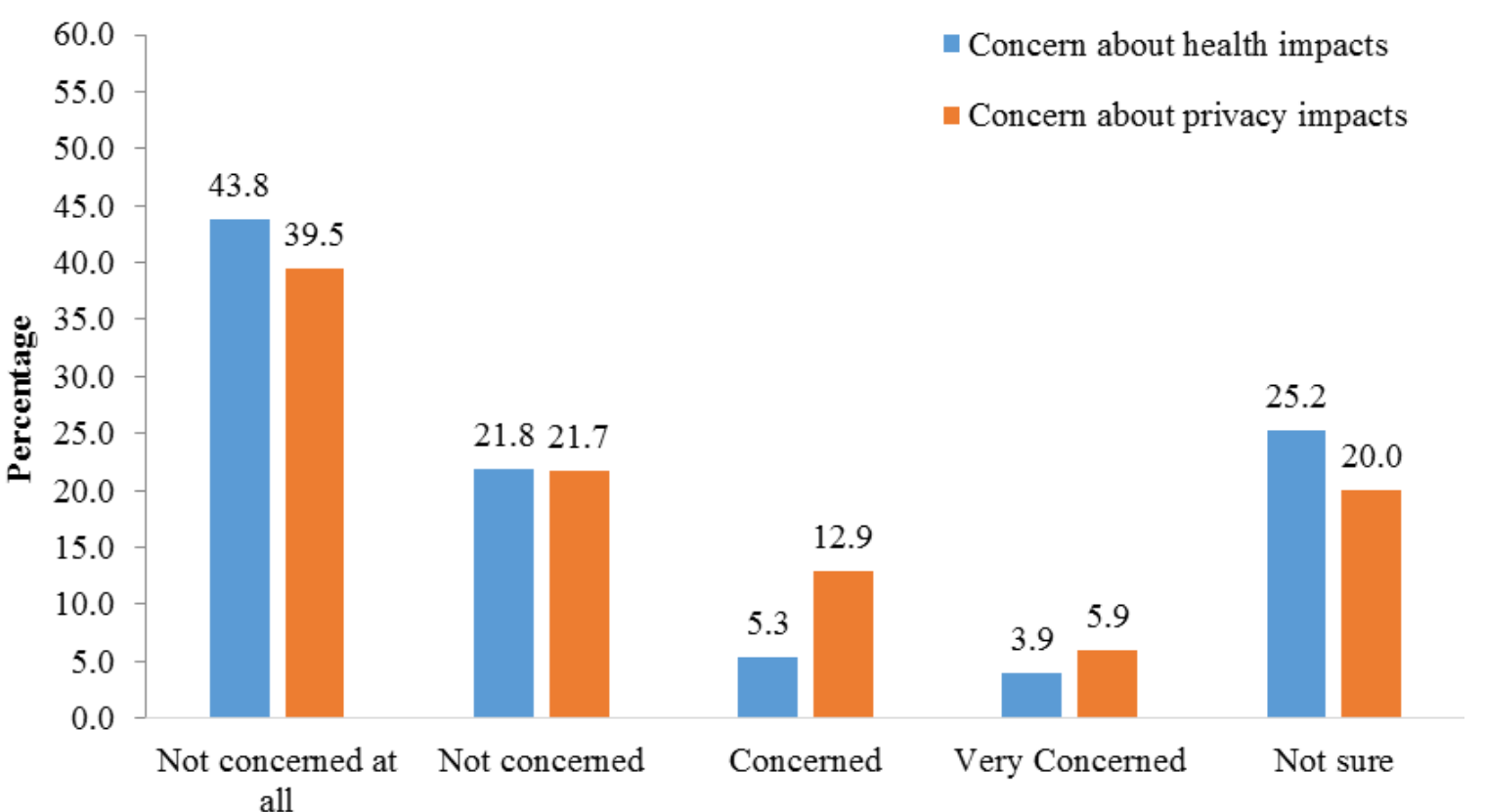

Level of concern

Figure 1. Concerns about the potential impact of smart meters on health $(n=609)$ and privacy (n=612) in 2015. 


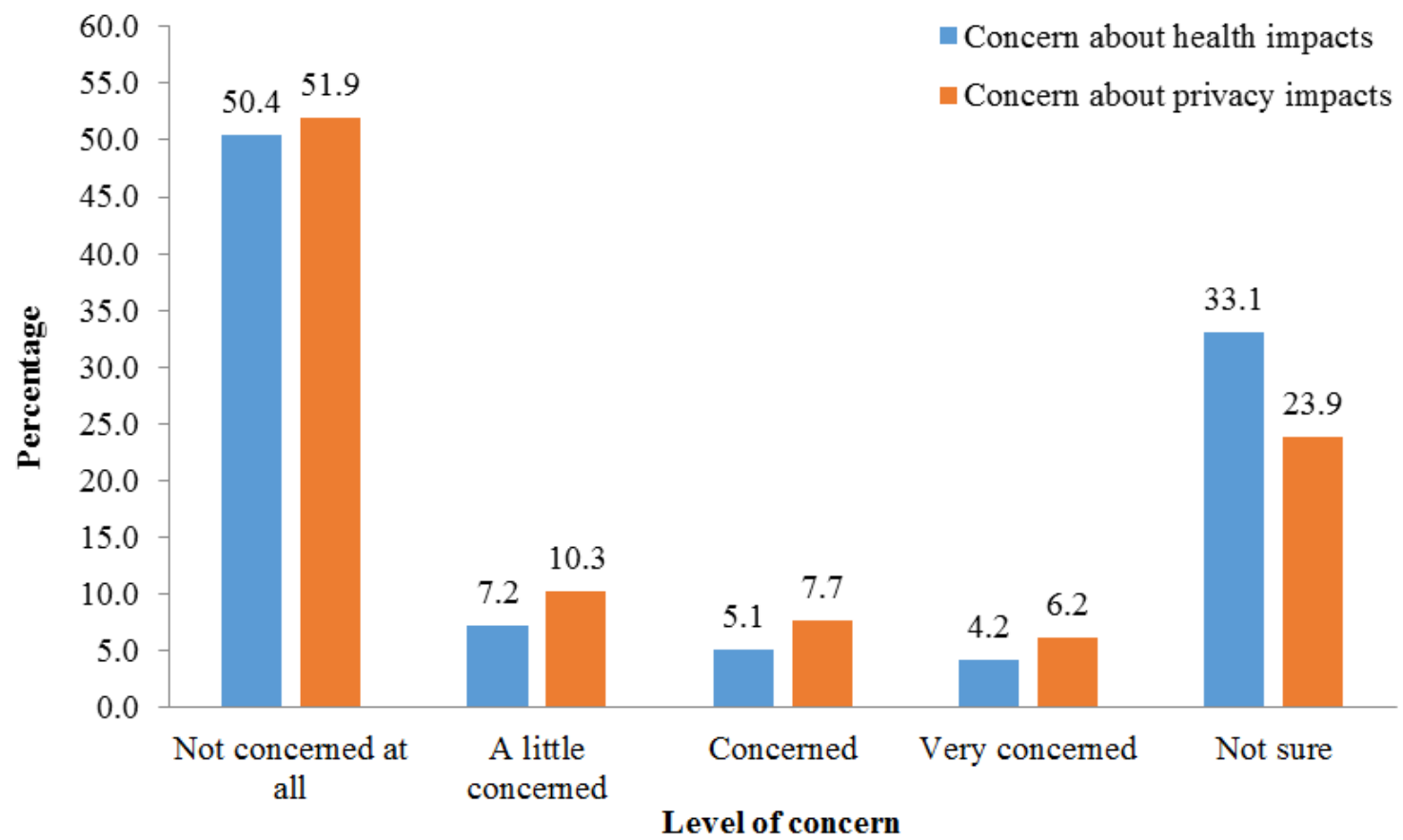

Figure 2. Concerns about the potential impact of smart meters on health ( $n=681)$ and privacy $(n=679)$ in 2016.

It should be noted that the Likert-type scales used for the preceding category of questions varied slightly between the 2015 and 2016 surveys and so were recoded as binary variables to make comparisons for these variables possible in the logistic regression, which included data from both years.

\subsection{Interest in Additional Information on Smart Meters}

Figure 3 shows the interest that 2016 survey respondents had in receiving different kinds of information on smart meters. The most requested type of information (31.3\%) was on how smart meters may help to reduce the electricity price, and the least requested type of information was on how smart meters may help to reduce power outages (26.5\%). Despite this degree of variation shown by respondents though, the fact that no more than $31.3 \%$ of respondents wanted any one kind of information on smart meters may indicate a general lack of interest in or knowledge of smart meters. Increased education on smart meters and the benefits they can provide may help to pique customers' interests in smart meters.

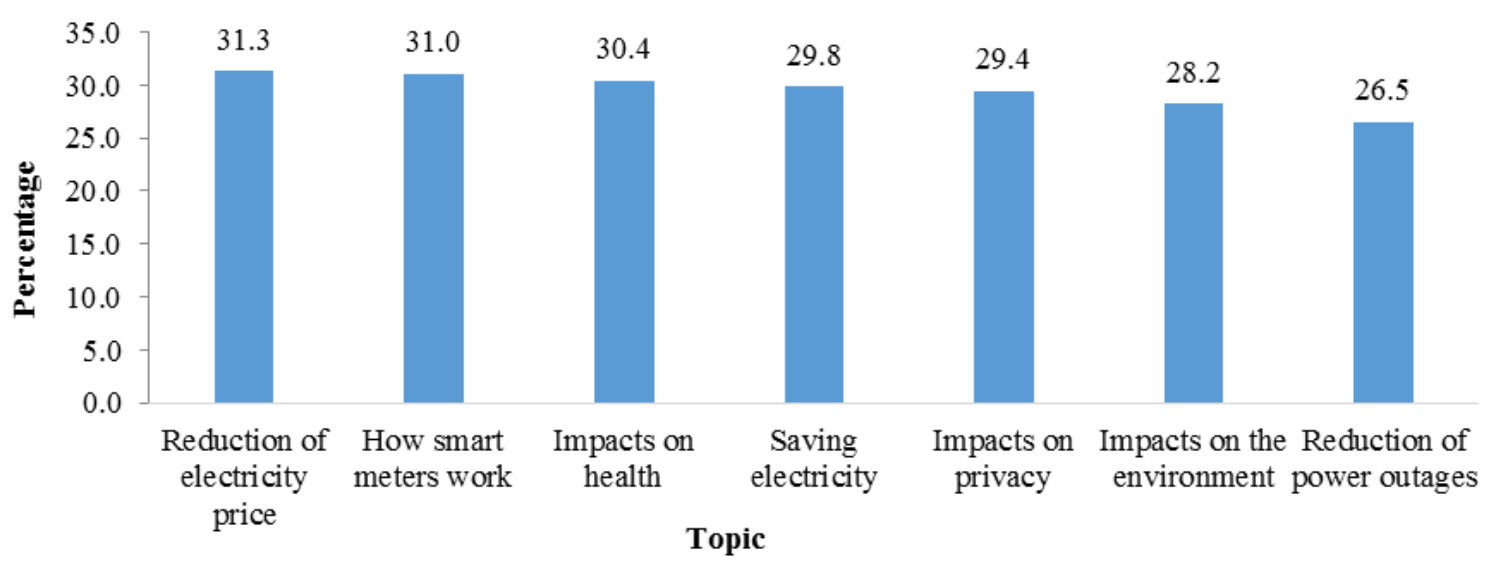

Figure 3. Additional information wanted on smart meters by topic $(n=684)$.

\section{Discussion and Implications}

The results of this study indicate a need for improved education on smart meters to bolster the benefits they can provide to utilities and electricity customers. As this research shows, many electricity customers may not be aware that they have a smart meter. Furthermore, those who are aware that they have a smart meter might not be accessing the information it provides. Education on smart meters should first raise electricity customers' awareness of the presence of smart meters. Next it is necessary to educate customers on how to access and use the information that smart meters can provide. However, education alone may not be effective if customers do not trust the source of information, which, in the case of smart meters, would tend to be utility companies. 
Effective education, in this regard, is not just about disseminating information, but also about building trust [18, 19]. If these efforts are coupled with the installation of inhome displays and dynamic electricity pricing, they will likely be even more effective.

One entity that may be particularly well-suited to educate electricity customers on smart meters is Extension, as Extension is often seen as an unbiased disseminator of information and thus is regarded as a trustworthy source [20, 21]. Currently, Vermont's Extension agency is not doing any work in regard to smart meters [22]. A partnership between Vermont's Extension educators and utility companies could facilitate dissemination of information regarding smart meters, including how to identify whether one has a smart meter and how to access the information it can provide. Extension and other potential educators on smart meters may find benefit in tailoring this work according to demographics. For example, these data indicate that those who live in units in multi-family dwellings and rent their homes are less likely to know that they have a smart meter than those who live in single-family dwellings and own their homes. Educational efforts focused on renters and those living in units in multifamily dwellings would be an effective way to increase awareness of smart meters. Additionally, Vermont residents are more concerned about potential privacy impacts of smart meters than they are potential health impacts. If Extension and other educators can learn what customers' concerns are about smart meters and why they have such concerns, they can provide educational materials that will help address these concerns.

Although some work has been done in Vermont to educate electricity customers about smart meters [12], it is unclear how widespread and effective these efforts have been. In addition to increased efforts to educate electricity customers on smart meters, more research is needed to better understand the following areas:

1. What baseline information, if any, electricity customers have on smart meters and where they obtained this information,

2. How the source of information on smart meters affects how electricity customers view and use them,

3. How information in different formats, such as in-home displays, affects electricity customers' electricity consumption,

4. What barriers electricity customers face in regard to changing their electricity consumption,

5. How different electricity pricing structures affect electricity customers' use of smart meters and electricity consumption, and

6. How different educational campaigns and programs on smart meters affect electricity customers' behavior.

In all, additional information in these areas can aid the development of interventions, such as educational campaigns, updates to how smart meter information is relayed to customers, and pricing structures, that increase the efficacy of smart meter utilization and the benefits they can provide.

\section{Conclusions and Recommendations}

Smart meters as a new technology have the capacity for many benefits, including reduced $\mathrm{CO}_{2}$ emissions and cost savings for electricity customers and utility companies. While some benefits have been realized from smart meter installation, such as decreased labor costs for utility companies and decreased severity of power outages, other benefits, such as reduced electricity use and cost for electricity customers, may not have been fully realized. Many of these benefits will depend on electricity customers changing their behavior in response to the real-time, or nearly real-time, pricing information that smart meters provide. If electricity customers are not aware that they have a smart meter, are not accessing the information that smart meters provide, and are not changing their behaviors in response to the information that smart meters provide, the benefits realized from this advanced technology are likely to remain limited.

As the results from this study show, smart meter technology in Vermont appears to be underutilized. Many residential electricity customers appear to be unaware that they have a smart meter, and many of those customers who do have a smart meter have not changed their electricity consumption as a result. Additionally, some residents report being concerned about smart meters' potential impacts on their health or privacy.

Since it is often regarded as an impartial and trusted source of information, Extension can play an influential role in disseminating information on smart meters. Extension and other educators can work with utility companies to build trust in smart meter technology and to spread knowledge of how to maximize the technology's benefits. Additional research on smart meters will help to improve the efficacy of education in regard to smart meters. The underutilization of smart meters means that many more benefits are available to be obtained from them, and education, especially when combined with additional research on smart meters, can play an important role in helping these benefits to be realized.

\section{Acknowledgements}

We would like to thank the editor and the reviewers for their comments and suggestions.

\section{References}

[1] U. S. Department of Energy: Office of Electricity Delivery \& Energy Reliability. (2016). "Recovery Act Smart Grid Document Collection: Key Documents from DOE's Recovery Act, 1-18." Accessed on May 22, 2016, https://www.smartgrid.gov/document/grid_impacts_benefits_a nd_lessons_learned.html.

[2] The Edison Foundation: Institute for Electric Innovation. (2014). Utility-Scale Smart Meter Deployments: Building Block of the Evolving Power Grid. Washington, DC. Accessed October 28, 2016, http://www.edisonfoundation.net/iei/publications/Documents/I EI_SmartMeterUpdate_0914.pdf. 
[3] U.S. Energy Information Administration. (2015). "How Many Smart Meters Are Installed in the United States, and Who Has Them?" Accessed on May 19, 2016, http://www.eia.gov/tools/faqs/faq.cfm?id=108\&t=3.

[4] Cook, B., J. Gazzano, Z. Gunay, L. Hiller, S. Mahajan, A. Taskan, and S. Vilogorac. (2012). "The Smart Meter and a Smarter Consumer: Quantifying the Benefits of Smart Meter Implementation in the United States." Chemistry Central Journal, 6 (Suppl 1). doi:http://dx.doi.org/10.1186/1752153X-6-S1-S5.

[5] Smith, R. (2009). "Smart meter, dumb idea?" The Wall Street Journal, Last modified April 27, 2009. http://www.wsj.com/articles/SB124050416142448555.

[6] Groothuis, P. A. and T. M. Mohr. (2014). "Do Consumers Want Smart Meters? Incentives or Inertia: Evidence from North Carolina and Lessons for Policy. Economics of Energy \& Environmental Policy, 3 (1): 53-67. doi:http://dx.doi.org/10.5547/2160-5890.3.1.pgro.

[7] U. S. Department of Energy: Office of Electricity Delivery \& Energy Reliability. (n.d.). "Vermont Transco, LLC." Accessed May 19, 2016,

https://www.smartgrid.gov/project/vermont_transco_llc_eener gy_vermont.html.

[8] E. Goldman, personal communication, February 9, 2016.

[9] U. S. Census. "Housing Vacancies and Homeownership." Last modified 2016, http://www.census.gov/housing/hvs/data/rates.html.

[10] Wang, Q., E. Trent, and R. Parsons. (2009). "Small Business Retirement Plan Participation and Needs for Information: Evidence from a Survey in Vermont.” Journal of Small Business and Entrepreneurship, 22 (2): 207-216.

[11] Honebein, P. C. (2010). "We Got a New Digital Electric Meter. Our Usage Went up 123\%. Our Bill Went up 65\%." The Electricity Journal, 23 (2): 76-82. doi:http://dx.doi.org/10.1016/j.tej.2010.01.007.

[12] Gram, D. (2014). "Big Push Is on for Smart Meters." Burlington Free Press, November 14. http://bfpne.ws/1qJjQe4.
[13] Jessoe, K. and D. Rapson. (2014). "Knowledge Is (Less) Power: Experimental Evidence from Residential Energy Use." American Economic Review, 104 (4): 1417-1438. doi:http://dx.doi.org/10.1257/aer.104.4.1417

[14] Mooney, C. (2015). "Why 50 Million Smart Meters Still Haven't Fixed America's Energy Habits.” The Washington Post, January 29.

https://www.washingtonpost.com/news/energy-

environment/wp/2015/01/29/americans-are-this-close-tofinally-understanding-their-electricitybills/?utm_term $=.51444142 \mathrm{c} 58 \mathrm{a}$

[15] P. Hines, personal communication, September 1, 2016.

[16] D. Fredman, personal communication, April 22, 2016.

[17] Hess, D. J. (2014). "Smart Meters and Public Acceptance: Comparative Analysis and Governance Implications." Health, Risk, \& Society, 16 (3): 243-258. doi:http://dx.doi.org/10.1080/13698575.2014.911821.

[18] Lineweber, D. C. (2011). "Understanding Residential Customer Support for - and Opposition to - Smart Grid Investments." The Electricity Journal, 24 (8): 92-100. doi: http://dx.doi.org/10.1016/j.tej.2011.09.005

[19] Wynne, B. (2006). "Public Engagement As a Means of Restoring Public Trust in Science - Hitting the Notes, but Missing the Music?” Community Genetics, 9 (3): 211-220. doi:http://dx.doi.org/10.1159/000092659.

[20] Laquatra, J., M. R. Pierce, and N. Helmholdt. (2009). "The Consumer Education Program for Residential Energy Efficiency." Journal of Extension, 47 (6). http://www.joe.org/joe/2009december/a6.php.

[21] Romich, E. (2015). "The Role of Extension in Energy Education." Journal of Extension, 53 (2). http://www.joe.org/joe/2015april/comm1.php.

[22] University of Vermont Extension. "Environment and Natural Resources.” Accessed October 30, 2016, $\mathrm{http}: / /$ www.uvm.edu/extension. 